\title{
Anticoagulation in the early phase of non-valvular atrial fibrillation-related acute ischemic stroke: where do we stand?
}

\author{
Luca Masotti, ${ }^{1}$ Elisa Grifoni, ${ }^{1}$ Alessandro Dei, ${ }^{1}$ Vieri Vannucchi, ${ }^{2}$ Federico Moroni, ${ }^{2}$ Grazia Panigada, ${ }^{3}$ \\ Stefano Spolveri, ${ }^{4}$ Giancarlo Landini ${ }^{2}$ \\ ${ }^{1}$ Internal Medicine, Stroke Unit and Center of Thromboembolic Diseases, San Giuseppe Hospital, Empoli (FI); ${ }^{2}$ Internal \\ Medicine, Stroke Unit and Center of Thromboembolic Diseases, Santa Maria Nuova Hospital, Florence; ${ }^{3}$ Internal Medicine \\ and Stroke Unit, SS. Cosma and Damiano Hospital, Pescia (PT); ${ }^{4}$ Internal Medicine and Stroke Unit, Borgo San Lorenzo \\ Hospital, Florence, Italy
}

\begin{abstract}
The balance between the risk of early stroke recurrence and hemorrhagic transformation represents the cornerstone of practical management of non-valvular atrial fibrillation (NVAF)-related acute ischemic stroke (AIS). Patients who receive antithrombotic therapy as secondary prevention in the early phase of NVAF-related AIS have a better prognosis compared with patients who do not receive antithrombotic treatment. Recently, the RAF study showed that the best efficacy/safety profile was associated with anticoagulation started between 4 and 14 days from stroke onset. Based on the RAF study, the 2018 American Heart Association/American Stroke Association (AHA/ASA) guidelines suggest starting anticoagulants between 4 and 14 days from stroke onset with a class of recommendation IIa. Strong evidence for the use of direct oral anticoagulants (DOACs) in the early phase of NVAF-related AIS is lacking, because this kind of patients were excluded from phase III randomized clinical trials (RCT) and ad hoc RCTs are ongoing. However, the real life evidence suggests that early starting time of DOACs in patients with NVAF-related AIS is safe and associated with low recurrence risk and all-cause mortality. In the present review the Authors provide an update on anticoagulation in the early phase of NVAF-related AIS with focus on DOACs.
\end{abstract}

\section{Introduction}

Non-valvular atrial fibrillation (NVAF)-related acute ischemic strokes (AIS) represent about one fourth of overall strokes and the most feared stroke subtype due to higher mortality and morbidity risk and more severe functional sequelae compared to other subtypes. ${ }^{1}$

Preventing stroke recurrences avoiding hemorrhagic transformation (HT) represents the cornerstone of

Correspondence: Luca Masotti, Internal Medicine II, San Giuseppe Hospital, viale Boccaccio 20, 50053 Empoli (FI), Italy.

E-mail: luca.masotti@tin.it

Key words: Stroke; dabigatran; rivaroxaban; apixaban; edoxaban; direct oral anticoagulants.

Conflict of interest: the authors declare no conflict of interest.

Received for publication: 5 November 2018.

Accepted for publication: 17 December 2018.

This work is licensed under a Creative Commons Attribution NonCommercial 4.0 License (CC BY-NC 4.0).

(C) Copyright L. Masotti et al., 2019

Licensee PAGEPress, Italy

Italian Journal of Medicine 2019; 13:24-31

doi:10.4081/itjm.2019.1111 secondary prevention in NVAF-related AIS. In the absence of secondary pharmacological prevention, the risk of early embolic stroke recurrence is about $1 \%$ per day in the first two weeks. ${ }^{2}$ HT represents the most feared complication in patients with AIS. Cardioembolic stroke represents one of the main risk factors for HT together with systemic thrombolysis, large vessel stroke etiology, large size infarcts and diabetes. ${ }^{3}$ The risk of HT in patients with cardioembolic stroke is three-five folds increased. ${ }^{3}$ The incidence of HT in patients with cardioembolic stroke is about $7-10 \%$ in the first two weeks from stroke onset. In the VISTA registry $80 \%$ of stroke recurrence and HT occurred within day 2 after stroke events. ${ }^{4}$ Both stroke recurrence and symptomatic HT are associated with poor prognosis in terms of morbidity, mortality, increased length of hospital stay (LOS) and neurological sequelae., ${ }^{2,3,5,6}$ Of note, the occurrence of HT is associated with delay of starting anticoagulation after stroke onset. ${ }^{6}$ Table 1 summarizes the classification of HT.

Oral anticoagulants represent the first therapeutic choice for secondary stroke prevention in atrial fibrillation (SPAF). ${ }^{7}$ A meta-analysis showed that, in patients with history of stroke, the number needed to treat (NNT) for preventing one stroke by using warfarin was 14 versus placebo and 24 versus antiplatelets. ${ }^{8}$ Patients who receive antithrombotic therapy as secondary prevention in the early phase of NVAFrelated AIS have a better prognosis compared with 
patients who do not receive antithrombotic treatment. ${ }^{4}$ In the VISTA registry the incidence of stroke recurrence, symptomatic intracranial bleeding, all-cause mortality and 90-day modified Rankin scale $(\mathrm{mRS}) \geq 4$ in patients with NVAF-related AIS not receiving antithrombotic treatment was $19.8 \%, 9.3 \%, 40.7 \%$ and $65.3 \%$, respectively compared with patients receiving vitamin $\mathrm{K}$ antagonists (VKAs) (10.6\%, 2.9\%, 25.5\% and $46.6 \%$, respectively) or VKAs plus antiplatelets $\left(6.7 \%, 1.9 \%, 17.8 \%\right.$ and $54.5 \%$, respectively). ${ }^{4}$ Baseline median National Institute of Health Stroke scale (NIHSS) score ranged from 16 in patients not receiving antithrombotics to 14 in patients receiving anticoagulants plus antiplatelets. ${ }^{4}$ The median starting time of anticoagulants in the VISTA registry was 2 days (interquartile range, 1-4). ${ }^{4}$

Despite the prognostic advantages, the optimal timing for starting anticoagulants in the acute phase of NVAF-related AIS remains a clinical dilemma. In patients receiving systemic thrombolysis none additional antithrombotic therapy is indicated in the first $24 \mathrm{~h}^{7}{ }^{7}$ Aspirin started after $24 \mathrm{~h}$ in patients receiving systemic thrombolysis or as soon as possible in patients not receiving systemic thrombolysis is the most appropriate secondary prevention in the first $48 \mathrm{~h}$ from stroke onset, whereas anticoagulation in this temporal window is unfavorable for the highest risk of HT. ${ }^{7,9}$ Recently, the RAF study showed that starting anticoagulation with VKAs [i.e. reaching international normalized ratio (INR) $\geq 2.0$ ] in AIS was associated with a 90-days incidence of transient ischemic attack (TIA)/stroke recurrence or systemic embolism of $6.4 \%$ (10.6\% in patients non receiving antithrombotic therapy, $\mathrm{P}=0.023)$ and hemorrhagic events of $5.4 \%$ (3.8\% in patients non receiving antithrombotic therapy, $\mathrm{P}=0.31$ ) and the best efficacy/safety profile was with a start time between 4 and 14 days. The mean time for reaching INR $\geq 2$ was $12.1 \pm 15.8$ days. $^{2}$ In the RAF study the mean baseline NIHSS score was $9.2 \pm 7.3$. About one fourth $(27.1 \%)$ of patients had large infarct size..$^{10}$ Definition of infarct size in the RAF study is summarized in Table 2 and examples of infarct size in Figure 1. Based on the RAF study, the latest (2018) American Heart Association/American Stroke Association (AHA/ASA) guidelines suggest to start anticoagulants between 4 and 14 days from stroke onset with a class of recommendation IIa. $^{7}$ This temporal window seems wide in the clinical context, and in the single patient the decision on when anticoagulants should be started, if closer to the fourth or fourteenth day, is difficult and at the same time fundamental. The analysis of subgroups of the RAF study showed that $\mathrm{CHA}_{2} \mathrm{DS}_{2}$-VASC score, NIHSS score, size of brain ischemic lesions and left atrial size each independently, could help in the appropriate timing for starting VKAs. ${ }^{10,11}$

\section{Direct oral anticoagulants in the secondary prevention of stroke}

Evidence for the use of direct oral anticoagulants (DOACs) in the acute phase of NVAF-related AIS is lacking, because this kind of patients were excluded from the phase III randomized clinical trials (RCTs) on DOACs in SPAF. ${ }^{12,13}$ Exclusion criteria related to AIS in phase III RCTs are summarized in Table 3. However about 14,000 patients enrolled in phase III RCTs on DOACs in SPAF had suffered from a previous TIA/stroke (Table 4). A post-hoc analysis of phase III RCTs comparing DOACs versus warfarin in SPAF showed a good efficacy/safety profile of DOACs in patients with history of previous TIA/stroke. Compared to warfarin, absolute risk reduction (ARR), relative risk

Table 1. Classification of hemorrhagic transformation in acute ischemic stroke.

\begin{tabular}{ll}
\hline Hemorrhage infarction type1 (HI) & Small isolated hyperdense petechiae \\
\hline Hemorrhage infarction type2 (HI2) & More confluent hyperdense petechiae throughout the infarct zone; without mass effect \\
\hline Parenchymal hematoma type1 (PH1) & Homogeneous hyperdensity occupying $<30 \%$ of the infarct zone without mass effect \\
\hline Parenchymal hematoma type2 (PH2) & Homogeneous hyperdensity occupying $>30 \%$ of the infarct zone with mass effect
\end{tabular}

Table 2. Definition of infarct size in RAF and RAF-NOACs studies.

\begin{tabular}{ll}
\hline Small infarct size & Less than $1.5 \mathrm{~cm}$ in the anterior or posterior circulation \\
\hline Medium infarct size & $\begin{array}{l}\text { Lesion in a cortical superficial branch of MCA, in the MCA deep branch, in the internal border zone territories, } \\
\text { in a cortical superficial branch of PCA, or in a cortical superficial branch of ACA }\end{array}$ \\
\hline Large infarct size & $\begin{array}{l}\text { Anterior lesions involved the complete territory of MCA, posterior cerebral artery, or anterior cerebral artery or } \\
\text { were in } 2 \text { cortical superficial branches of the MCA, in a cortical superficial branch of MCA associated with the } \\
\text { MCA deep branch, or in }>1 \text { artery territory }(e . g ., \text { MCA associated with anterior cerebral artery territory); lesions } \\
\geq 1.5 \mathrm{~cm} \text { in the brain stem or cerebellum }\end{array}$
\end{tabular}

MCA, middle cerebral artery; PCA, posterior cerebral artery; ACA, anterior cerebral artery. 
reduction (RRR) and NNT were $0.78 \%, 13.7 \%$ and 127 , respectively, for preventing stroke or systemic embolism, while ARR, RRR and NNT were $0.88 \%, 46 \%$ and 113 , respectively, for preventing intracranial bleeding. ${ }^{14}$

Despite the absence of strong literature evidence, DOACs seem to represent a great opportunity in patients with NVAF-related AIS, due to their favorable pharmacological and safety profiles. Based on Expert opinion, guidelines suggest starting DOACs immediately in patients with NVAF-related TIA, after $\geq 3,6-8$ and 12-14 days in mild (NIHSS score $<8$ ), moderate (NIHSS 8-16) or severe (NIHSS score $>16$ stroke)..$^{15}$
Direct oral anticoagulants in the early phase of non-valvular atrial fibrillation-related acute ischemic stroke: update on available evidence

Phase II clinical trials

The TRIPLE-Axel was a phase II RCT comparing low dose rivaroxaban $(10 \mathrm{mg})$ for five days followed by full dose $(20 \mathrm{mg}$, or $15 \mathrm{mg}$ in patients with creatinine clearance $30-49 \mathrm{~mL} / \mathrm{min}$ ) versus warfarin with a target INR of 2.0-3.0 for four weeks in 183 patients with mild (NIHSS $\leq 4)$ NVAF-related AIS. This trial showed no difference between the two arms

Table 3. Exclusion criteria in phase III randomized clinical trials on direct oral anticoagulants in stroke prevention in atrial fibrillation.

\begin{tabular}{ll}
\hline RCT & Exclusion criteria \\
\hline RE-LY & $\begin{array}{l}\text { Stroke with severe functional sequelae (modified Rankin scale) in the previous } 6 \text { months } \\
\text { Acute stroke in the previous two weeks }\end{array}$ \\
\hline ROCKET-AF & $\begin{array}{l}\text { Stroke with severe functional sequelae (modified Rankin scale) in the previous } 3 \text { months } \\
\text { Acute stroke in the previous two weeks TIA in the previous } 3 \text { days }\end{array}$ \\
\hline ARISTOTLE & $\begin{array}{l}\text { Stroke in the previous week (44 patients suffering from TIA or stroke in the previous 7-14 days and 187 suffering } \\
\text { from TIA or stroke in the previous } 14-30 \text { days were enrolled in the study) }\end{array}$ \\
\hline ENGAGE-AF & Stroke in the previous 30 days \\
\hline
\end{tabular}

RCT, randomized controlled trials; TIA, transient ischemic attack
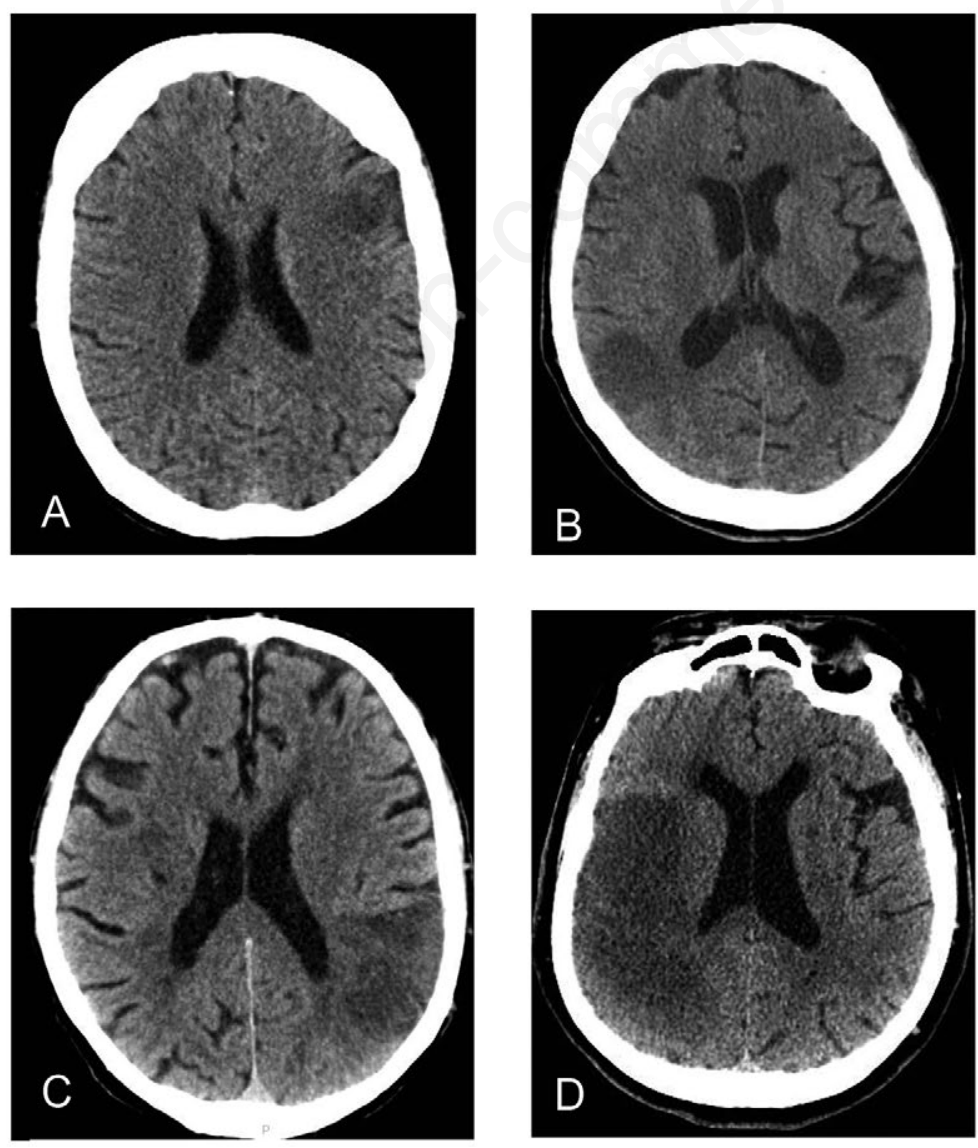

Figure 1. Examples of infarct size: A) supratentorial cortical small infarct; B) supratentorial cortical moderate infarct size; C) supratentorial cortical large infarct size; D) supratentorial very large infarct size; E) infratentorial (cerebellum) large infarct size. 
in the primary composite endpoint of stroke recurrence and/or new intracranial bleeding. ${ }^{16}$ Patients receiving rivaroxaban showed a significant shorter LOS (4.0 vs 6.0 days, $\mathrm{P}<0.001) .{ }^{16}$

\section{Phase III and phase IV clinical trials}

Until now, phase III and phase IV clinical trials aimed to analyze efficacy and safety of DOACs in the early phase of NVAF-related AIS are ongoing and results have not been published yet. Table 5 summarizes the design of planned clinical trials in this context.

\section{Real life evidence}

In the last years a lot of literature evidence about the introduction of DOACs in the early phase of NVAFrelated AIS was available. More recently, Masotti et al. provided a summary of this literature evidence. ${ }^{17}$ The Authors analyzed Pubmed database searching for published articles until June 2018 reporting data on 90day prognosis of patients receiving DOACs in the first two weeks after NVAF-related AIS. They built their search by combining the terms oral anticoagulants, stroke, acute, early by using the Boolean operators $A N D / O R$. The search was restricted to English language articles, adults ( $\geq 18$ years), words in title/abstract. Finally, the search strategy was refined by reviewing the bibliography of retrieved articles. Only studies including DOACs and reporting endpoints, such as 90-day TIA/stroke recurrence, HT or intracranial bleeding and all-cause mortality were considered for the analysis. The Authors identified eight studies ${ }^{18-25}$ satisfying the criteria of their search, with different methodology (five prospective observational, two retrospective and one prospective, open label, single arm design). Overall, the eight studies included 2187 patients (49.3\% females) of whom 830 were treated with rivaroxaban, 729 with dabigatran, 475 with apixaban and 6 with edoxaban. For 147 data on the type of DOAC used were not available. In all the studies mean or median age of patients was over 70 years. About one third of patients were treated with urgent reperfusion therapy, and about one fifth of patients had large infarct size. Median or mean NIHSS ranged from 2 to 8 points. Median time of starting DOACs ranged from 2 to 8 days, and in seven out of eight selected studies, median or mean starting time was $\leq 5$ days. About $42 \%$ of patients received low dose of DOACs. Ninety-day TIA/stroke recurrence, HT/intracranial bleeding and all-cause mortality occurred in $2.3 \%, 0.93 \%$ and $1.5 \%$ of patients, respectively. The Authors concluded that, awaiting results of phase III RCTs, the findings of their overview could open a new scenario, supporting the use of DOACs as the possible treatment of choice in the early phase of NVAF-related AIS, and highlighting that 90day prognostic outcomes were lower than those reported in the previous studies (Table 6).,17 However, the Authors, recognized that their review had limitations. In fact, the interpretation of their results should take into account that the selected studies had different designs, none of them had a comparison group, the average stroke severity was mild (median or mean NIHSS at hospital admission is $\leq 8$ ), about $40 \%$ of patients were treated with low doses of DOACs, even if the reason of dose reduction was almost never reported and finally, the follow-up was limited to 90 days.

Recently, data on the 2-year follow-up of the SAMURAI-NVAF registry, examining the long-term risk-benefit profile among patients receiving warfarin

Table 4. General characteristics of patients with history of previous transient ischemic attack/stroke enrolled in phase III randomized clinical trials.

\begin{tabular}{|c|c|c|c|c|c|}
\hline & $\begin{array}{c}\text { RE-LY } \\
\text { dabigatran } 110 \mathrm{mg}\end{array}$ & $\begin{array}{c}\text { RE-LY } \\
\text { dabigatran } 150 \mathrm{mg}\end{array}$ & $\begin{array}{l}\text { ROCKET-AF } \\
\text { rivaroxaban }\end{array}$ & $\begin{array}{c}\text { ARISTOTLE } \\
\text { apixaban }\end{array}$ & $\begin{array}{l}\text { ENGAGE-AF } \\
\text { edoxaban }\end{array}$ \\
\hline Number & 1195 & 1233 & 3754 & 1694 & 5973 \\
\hline Mean age (years) & $70.7 \pm 9.4$ & $70.8 \pm 10.1$ & $\begin{array}{c}71(64-76) \\
\text { Median (IQR) }\end{array}$ & $70.1 \pm 9.5$ & $70.4 \pm 9.2$ \\
\hline Females & $35.9 \%$ & $37.8 \%$ & $39 \%$ & $37 \%$ & $38.2 \%$ \\
\hline $\mathrm{CHADS}_{2}$ score $\geq 3$ & $90 \%$ & $90.2 \%$ & $\mathrm{nr}^{*}$ & $92 \%$ & $\mathrm{nr} * *$ \\
\hline Aspirin at moment of enrollment & $39.9 \%$ & $39.7 \%$ & $38 \%$ & $31 \%$ & $28.2 \%$ \\
\hline Previous AMI & $\mathrm{nr}$ & $\mathrm{nr}$ & $14 \%$ & $17 \%$ & $\mathrm{nr}$ \\
\hline Systemic blood hypertension & $77 \%$ & $77.3 \%$ & $85 \%$ & $83 \%$ & $86.2 \%$ \\
\hline Diabetes & $22.4 \%$ & $23.7 \%$ & $25 \%$ & $26 \%$ & $26.6 \%$ \\
\hline Heart failure & $\mathrm{nr}$ & $\mathrm{nr}$ & $51 \%$ & $27 \%$ & $42.4 \%$ \\
\hline Paroxysmal AF & $\mathrm{nr}$ & $\mathrm{nr}$ & $19 \%$ & $\mathrm{nr}$ & $26.1 \%$ \\
\hline Persistent or permanent AF & $\mathrm{nr}$ & $\mathrm{nr}$ & $81 \%$ & $\mathrm{nr}$ & $73.9 \%$ \\
\hline
\end{tabular}

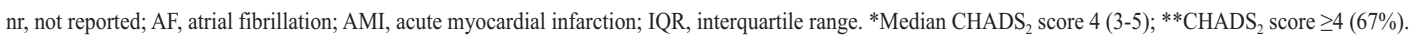


Table 5. Study design of ongoing phase III and phase IV clinical trials on direct oral anticoagulants in the early phase of non-valvular atrial fibrillation related acute ischemic stroke (source clinicaltrials.gov 2018, October 31).

\begin{tabular}{|c|c|c|c|c|c|c|c|c|}
\hline Study & Design & $\begin{array}{l}\text { Inclusion } \\
\text { criteria }\end{array}$ & DOAC & Dose & Comparators & $\begin{array}{l}\text { DOAC } \\
\text { starting time }\end{array}$ & $\begin{array}{c}\text { Expected } \\
\text { number }\end{array}$ & $\begin{array}{l}\text { Primary } \\
\text { endpoints }\end{array}$ \\
\hline RELAXED & $\begin{array}{l}\text { Multicenter } \\
\text { observational } \\
\text { non- } \\
\text { interventional } \\
\text { single arm }\end{array}$ & $\begin{array}{l}\text { TIA or AIS } \\
\text { in the middle } \\
\text { cerebral artery } \\
\text { territory }\end{array}$ & Rivaroxaban & $\begin{array}{l}\mathrm{ClCr}>50 \mathrm{~mL} / \\
\mathrm{min} 15 \mathrm{mg} ; \\
\mathrm{ClCr} 15-49 \\
\mathrm{~mL} / \mathrm{min} 10 \mathrm{mg}\end{array}$ & None & Within 30 days & 2000 pts & $\begin{array}{l}\text { 3-months stroke } \\
\text { recurrence } \\
\text { 3-months major } \\
\text { bleeding }\end{array}$ \\
\hline TIMING & $\begin{array}{l}\text { Multicenter, } \\
\text { open-label, } \\
\text { RCT }\end{array}$ & $\begin{array}{l}\text { AIS within } \\
72 \mathrm{~h} \text { from onset }\end{array}$ & All DOACs & $\begin{array}{l}\text { According to } \\
\text { habitual } \\
\text { clinical } \\
\text { practice }\end{array}$ & $\begin{array}{l}\text { Early start } \\
\text { ( } \leq 4 \text { days) } \\
\text { versus } \\
\text { delayed } \\
\text { (5-10 days) } \\
\text { start of } \\
\text { DOAC } \\
\text { therapy }\end{array}$ & $\begin{array}{l}\leq 4 \text { days or } \\
5-10 \text { days }\end{array}$ & 3000 pts & $\begin{array}{l}\text { 3-months } \\
\text { composite stroke } \\
\text { recurrence, } \\
\text { intracranial } \\
\text { bleeding and } \\
\text { all-cause } \\
\text { mortality }\end{array}$ \\
\hline RASS & $\begin{array}{l}\text { Observational } \\
\text { single arm }\end{array}$ & $\begin{array}{l}\text { Acute minor } \\
\text { stroke } \\
\text { (NIHSS score } \\
<8 \text { ) within } \\
\text { 24-h from } \\
\text { onset or TIA }\end{array}$ & Rivaroxaban & NR & None & NR & 100 pts & Symptomatic HT \\
\hline SEDMAN & $\begin{array}{l}\text { Prospective } \\
\text { multicenter } \\
\text { case-control } \\
\text { investigator- } \\
\text { initiated study }\end{array}$ & $\begin{array}{l}\text { AIS or TIA in } \\
\text { the last 14-days }\end{array}$ & Dabigatran & $\begin{array}{l}\text { According to } \\
\text { habitual clinical } \\
\text { practice }\end{array}$ & Acenocumarol & $<14$ days & $500 \mathrm{pts}$ & $\begin{array}{l}\text { 1-year } \\
\text { TIA/stroke or } \\
\text { systemic } \\
\text { embolism 1-year } \\
\text { CRNM and } \\
\text { major bleeding }\end{array}$ \\
\hline START & $\begin{array}{l}\text { Multicenter } \\
\text { interventional } \\
\text { parallel- } \\
\text { assignment } \\
\text { outcomes- } \\
\text { assessor RCT }\end{array}$ & $\begin{array}{l}\text { AIS (infarct } \\
\text { size }>1.5 \mathrm{~cm} \\
\text { or NIHSS } \\
\text { score }>4 \text { ) }\end{array}$ & All DOACs & $\begin{array}{l}\text { According to } \\
\text { habitual } \\
\text { clinical } \\
\text { practice }\end{array}$ & $\begin{array}{l}\text { Early start } \\
\text { versus delayed } \\
\text { start of DOAC } \\
\text { therapy }\end{array}$ & $\begin{array}{l}3 \text { days } v s \\
6 \text { days } v s \\
10 \text { days } v s \\
14 \text { days }\end{array}$ & 1000 pts & $\begin{array}{l}\text { 30-day stroke } \\
\text { recurrence } \\
30 \text {-day any } \\
\text { symptomatic } \\
\text { HT, other } \\
\text { intracranial } \\
\text { bleeding or } \\
\text { major } \\
\text { extracranial } \\
\text { bleeding }\end{array}$ \\
\hline AOD & $\begin{array}{l}\text { Prospective } \\
\text { observational }\end{array}$ & AIS & All DOACs & $\begin{array}{l}\text { According to } \\
\text { habitual } \\
\text { clinical } \\
\text { practice }\end{array}$ & None & NR & 420 pts & $\begin{array}{l}\text { 12-month stroke } \\
\text { recurrence }\end{array}$ \\
\hline ATIS-NVAF & $\begin{array}{l}\text { Multicenter } \\
\text { open-label } \\
\text { RCT }\end{array}$ & $\begin{array}{l}\text { TIA or AIS in } \\
\text { the last } 8 \text { days } \\
\text { and NVAF and } \\
\text { past history of } \\
\text { atherothrombotic } \\
\text { diseases }\end{array}$ & $\begin{array}{l}\text { All DOACs } \\
\text { or warfarin } \\
\text { plus dual or } \\
\text { mono } \\
\text { antiplatelet } \\
\text { drug }\end{array}$ & $\begin{array}{l}\text { According to } \\
\text { habitual } \\
\text { clinical } \\
\text { practice } \\
\text { (warfarin INR } \\
2.0-3.0 \text { ) }\end{array}$ & $\begin{array}{l}\text { DOAC or } \\
\text { warfarin plus } \\
\text { DAPT } v s \\
\text { DOAC } \\
\text { or warfarin } \\
\text { plus MAPT }\end{array}$ & NR & 400 & $\begin{array}{l}\text { Composite } \\
\text { cardiovascular } \\
\text { events and major } \\
\text { bleeding }\end{array}$ \\
\hline ELAN & $\begin{array}{l}\text { Multicenter } \\
\text { interventional } \\
\text { assessor- } \\
\text { blinded RCT }\end{array}$ & AIS & All DOACs & $\begin{array}{l}\text { According to } \\
\text { habitual clinical } \\
\text { practice }\end{array}$ & $\begin{array}{l}\text { Early versus } \\
\text { late treatment } \\
\text { by DOACs }\end{array}$ & $\begin{array}{l}\text { Early: } \\
48 \text { h in small } \\
\text { and moderate } \\
\text { infarct size; } \\
6+1 \text { day in } \\
\text { large infarct } \\
\text { size } \\
\text { Late: } \\
3+1 \text { day small } \\
\text { infarct size; } \\
6+1 \text { day } \\
\text { moderate } \\
\text { infarct size; } \\
\text { 12+2 large } \\
\text { infarct size }\end{array}$ & 2000 & $\begin{array}{l}\text { 30-day } \\
\text { composite stroke } \\
\text { recurrence, } \\
\text { systemic } \\
\text { embolism, } \\
\text { major bleeding, } \\
\text { cardiovascular } \\
\text { death }\end{array}$ \\
\hline
\end{tabular}

DOAC, direct oral anticoagulant; TIA, transient ischemic attack; AIS, acute ischemic stroke; CrCl, creatinine clearance; RCT, randomized clinical trial; NIHSS, National Institute of Heath Stroke scale; NR, not reported; HT, hemorrhagic transformation; CRNM, clinically relevant non major bleeding; NVAF, non-valvular atrial fibrillation; DAPT, dual antiplatelet therapy; MAPT, mono antiplatelet therapy; INR, international normalized ratio. 
or DOACs, were published: estimated cumulative incidences of stroke and systemic embolism within 2 years were similar between warfarin and DOACs users, but deaths and intracranial hemorrhages were significantly lower among the latter. ${ }^{26}$

\section{Implications for clinical practice}

The decision on the optimal time for starting anticoagulants in the acute phase of NVAF-related AIS remains a challenge. Before DOACs era the introduction of anticoagulation in the early phase of NVAF-related AIS was strongly underused. In a previous multicenter study performed in Tuscany at the beginning of this decade (2011), only about one fourth of patients with NVAF-related AIS received VKAs before hospital discharge. More than one half of patients were discharged on antiplatelet therapy. ${ }^{5}$

Defining the risk of stroke recurrence and HT is of fundamental importance for anticoagulation starting time. Combining patients of RAF and RAF-NOACs studies, Paciaroni et al. found that older age, infarct size $\geq 1.5 \mathrm{~cm}$ and severe left atrial enlargement are significantly associated with long-term prognosis in patients suffering from NVAF-related AIS. Therefore, the Authors derived and validated the ALESSA score (Table 7), which has a good predictive power in predicting stroke recurrence (area under the receiving operating characteristic curve 0.646 [95\% confidence interval (CI): 0.529-0.763], while the power to predict hemorrhagic events is low (AUC $0.407,95 \%$ CI: 0.275 $0.540){ }^{27}$

After DOACs marketing, the confidence in their use in patients with NVAF and venous thromboembolism together with their favorable pharmacological profile (rapid onset of action and lower risk of intracranial bleeding compared with VKAs) has led physicians to consider the use of DOACs in the early phase of NVAF-related AIS despite the absence of data in phase III RCTs. In a previous study performed in the Internal Medicine Ward of Santa Maria Nuova Hospital, Florence, Italy, Moroni et al. demonstrated that in the era of DOACs the percentage of patients with NVAF-related AIS who underwent anticoagulation before hospital discharge was $69.5 \%$ and this percentage increased from $62.5 \%$ in 2014 to $88 \%$ in $2016 .{ }^{18}$ In this study, enclosed with the review by Masotti et al., 90-day stroke recurrence, intracranial bleeding and all-cause mortality were $1 \%, 0 \%$ and $3 \%$ respectively. In the study by Moroni et al. median mRS at hospital discharge and after 90-day in patients receiving DOACs was 3 (1-4) and 2 (1-3), respectively. In patients not receiving DOACs $\mathrm{mRS}$ at hospital discharge and after 90-day was 5 (4-5) and 5 (4-6), respectively. 90-day all-cause mortality in patients not receiving DOACs was $57.1 \%$. Age, severe neurological sequelae and renal impairment were associated with failure to prescribe DOACs. ${ }^{18}$ Similar results were found by Deguchi et al. who found that warfarin use at admission, higher mRS score and renal impairment were associated with failure to prescribe DOACs. ${ }^{28}$ In the study by Moroni et al. it was observed that the delay in DOACs introduction was associated with infarct size. In fact, patients with small stroke received DOACs with a delay of $3.2 \pm 2.2$ days, those with a medium stroke received DOACs after 5.2 \pm 3.3 days, and those with a large stroke received DOACs after 6.4 \pm 2.9 days. Moreover, the delay of DOACs starting was associated with NIHSS score. Patients with NIHSS scores $<8$ received DOACs with a delay of $4.1 \pm 3.1$ days, those with NIHSS scores in the range 8-16 with a delay of $6.7 \pm 3.7$ days, and the delay for patients with NIHSS scores $>16$ was $6.5 \pm 3.8$ days $^{18}$ ). Similar results were found by Deguchi et al. ${ }^{29}$ in the SAMURAI Study in which the delay of DOACs introduction was associated with severity of stroke and by Macha et al. who found that the delay in DOACs starting time was associated with infarct size and localization. ${ }^{30}$ Of note

Table 6. 90-day prognosis in patients with non-valvular atrial fibrillation related acute ischemic stroke according to different antithrombotic treatment.

\begin{tabular}{lccccc}
\hline & Number & Age (years) & $\begin{array}{c}\text { Median } \\
\text { NIHSS } \\
\text { score } \\
\text { Median } \\
\text { (IQR) }\end{array}$ & $\begin{array}{c}\text { 90-day stroke } \\
\text { recurrence }\end{array}$ & $\begin{array}{c}\text { 90-day } \\
\text { intracranial } \\
\text { bleeding } \\
\text { all-cause } \\
\text { mortality }\end{array}$ \\
\hline VISTA Registry (no antithrombotics) & 182 & $77.1 \pm 9.0$ & $16(11-21)$ & $19.8 \%$ & $9.3 \%$ \\
\hline VISTA Registry (antiplatelets) & 162 & $75.8 \pm 10.0$ & $15(11-19)$ & $8.6 \%$ & $1.9 \%$ \\
\hline VISTA Registry (anticoagulants) & 518 & $73.4 \pm 10.1$ & $14(10-18)$ & $10.6 \%$ & $2.9 \%$ \\
\hline RAF study (anticoagulants) & 766 & $77.2 \pm 9.5$ & $6(3-12.5)$ & $6.4 \%$ & $2.7 \%$ \\
\hline Real life studies with DOACs pooled & 2187 & $73.5 \pm 13-82.1 \pm 8$ (range) & $2-8($ range) & $2.3 \%$ & $5.4 \%$ \\
\hline
\end{tabular}

NIHSS, National Institute of Heath Stroke scale; IQR, interquartile range; NR, not reported. 
Macha et al. found that the delay of DOACs starting time progressively increased whether patients had TIA, non-extensive supratentorial infarct, infratentorial infarct or extensive supratentorial infarct, respectively. ${ }^{30}$ More interestingly, in the RAF-NOACs study Paciaroni et al. found a 5.2\% 90-day incidence of the composite endpoint TIA/stroke recurrence, systemic embolism and major intracranial and extracranial bleeding compared to $12.6 \%$ in the RAF study. The best temporal window associated with lower risk of the composite endpoint was between 3 and 14 days from stroke onset, while starting DOACs within $48 \mathrm{~h}$ or after 14 days was associated with a 12.4 and 9.1\% 90-day incidence of the composite endpoint, respectively. ${ }^{10,19}$

Consequently, based on available literature evidence and recommendations, it could be speculated about the fact that patients with small supratentorial infarct size, mild stroke severity (NIHSS score $<8$ ) and low HT risk could start anticoagulation close to third-fourth day, while patients with large supratentorial infarct size or infratentorial infarct, serious stroke severity (NIHSS score $>16$ ) and high HT risk could start anticoagulation close to fourteenth day. Patients with medium infarct size, mild stroke severity (NIHSS 8-16) and low HT risk could start anticoagulation between 6 and 10 days from stroke onset. It should be remarked that in the RAF study, patients with high $\mathrm{CHA}_{2} \mathrm{DS}_{2}$-VASC score and

Table 7. The ALESSA score.

\begin{tabular}{lc}
\hline Variable & Score \\
\hline Age $\geq 80$ years & 2 \\
\hline Age $70-79$ years & 1 \\
\hline Infarct size $>1.5 \mathrm{~cm}$ & 1 \\
\hline Severe left atrial enlargement & 1 \\
\hline
\end{tabular}

moderate-severe left atrial enlargement were at higher risk of composite endpoint TIA/stroke recurrence and HT, whereas patients receiving bridging therapy with low molecular weight heparins were at higher risk of HT. Therefore, additional factors other than infarct size and NIHSS score should be taken into account when deciding about DOACs starting time. Table 8 summarizes variables favoring the choice to early starting (within one week) of DOACs in NVAFrelated AIS.

\section{Conclusions}

Anticoagulation represents the best choice for secondary prevention in patients suffering from NVAF-related AIS. The optimal timing for starting anticoagulation in this context remains unclear despite the RAF study showed that starting anticoagulation within the 4 to 14 days temporal window from stroke onset is associated with lower risk of stroke recurrence and/or HT. ${ }^{10}$ Awaiting findings from ongoing prospective RCTs on DOACs introduced in the early phase of NVAF-related AIS, the real life evidence suggests that starting DOACs in this context seems safer and associated with lower stroke recurrence and all-cause mortality risk compared to traditional treatment.

\section{References}

1. Perera KS, Vanassche T, Bosch J, et al. Global survey of the frequency of atrial fibrillation-associated stroke. Embolic stroke of undetermined source global registry. Stroke 2016;47:2197-02.

2. Paciaroni M, Agnelli G, Micheli S, Caso V. Efficacy and safety of anticoagulant treatment in acute cardioembolic stroke: a meta-analysis of randomized controlled trials. Stroke 2007;38:423-30.

Table 8. Pros and cons for early (within 7 days) introduction of direct oral anticoagulant.

\begin{tabular}{ll}
\hline Pros & Cons \\
\hline TIA & Moderate-large infarct size \\
Small infarct size & NIHSS score $\geq 8$ \\
NIHSS score $<8$ & $\mathrm{mRS} \geq 4$ \\
mRS score $\leq 3$ & $\mathrm{PH} 1 \mathrm{HT}$ \\
Any $\mathrm{HT}$ absent & $\mathrm{PH} 2 \mathrm{HT}$ \\
$\mathrm{CHA}_{2} \mathrm{DS}_{2}$-VASC $\geq 4$ & $\mathrm{CHA}_{2} \mathrm{DS}_{2}$-VASC $<4$ \\
Moderate-severe left atrial enlargement & Left atrial enlargement absent \\
\hline To be considered as adjunctive factors to delay DOACs starting time: \\
$\begin{array}{ll}\text { - Neurological instability } & \\
\text { - Need for gastrostomy or other surgical procedures } \\
\text { - Need for carotid surgery }\end{array}$ \\
$\begin{array}{l}\text { - Uncontrolled blood hypertension } \\
\text { - Infratentorial localization }\end{array}$ \\
- Age $\geq 85$ years
\end{tabular}

TIA, transient ischemic attack; NIHSS, National Institute of Health Stroke scale; mRS, modified Rankin scale; PH, parenchymal hematoma; HT, hemorrhagic transformation; DOACs, direct oral anticoagulants. 
3. Paciaroni M, Agnelli G, Corea F, et al. Early hemorrhagic transformation of brain infarction: rate, predictive factors, and influence on clinical outcome: results of a prospective multicenter study. Stroke 2008;39:2249-56.

4. Abdul-Rahim AH, Fulton RL, Frank B, et al. VISTA collaborators. Association of improved outcome in acute ischaemic stroke patients with atrial fibrillation who receive early antithrombotic therapy: analysis from VISTA. Eur J Neurol 2015;22:1048-55.

5. Masotti L, Innocenti R, Spolveri S, et al. Stroke prevention in atrial fibrillation: findings from Tuscany FADOI Stroke Registry. Ital J Med 2015;9:134-40.

6. Paciaroni M, Bandini F, Agnelli G, et al. Hemorrhagic transformation in patients with acute ischemic stroke and atrial fibrillation: time to initiation of oral anticoagulant therapy and outcomes. JAHA 2018 [In press].

7. Powers WJ, Rabinstein AA, Ackerson T, et al. 2018 guidelines for the early management of patients with acute ischemic stroke. A guideline for healthcare professionals from the American Heart Association/ American Stroke Association. Stroke 2018;49:e46-e110.

8. Hart RG, Pearce LA, Aguilar MI. Meta-analysis: antithrombotic therapy to prevent stroke in patients who have nonvalvular atrial fibrillation. Ann Intern Med 2009;146:857-67.

9. Sandercock PA, Counsell C, Kamal AK. Anticoagulants for acute ischaemic stroke. Cochrane Database Syst Rev 2008;(4):CD000024.

10. Paciaroni M, Agnelli G, Falocci N, et al. Early recurrence and cerebral bleeding in patients with acute ischemic stroke and atrial fibrillation: effect of anticoagulation and its timing: the RAF study. Stroke 2015;46:2175-82.

11. Paciaroni M, Agnelli G, Falocci N et al. Prognostic value of trans-thoracic echocardiography in patients with acute stroke and atrial fibrillation: findings from the RAF study. J Neurol 2016;263:231-7.

12. Ruff CT, Giugliano RP, Braunwald E, et al. Comparison of the efficacy and safety of new oral anticoagulants with warfarin in patients with atrial fibrillation: a metaanalysis of randomised trials. Lancet 2014;383:955-62.

13. Masotti L, Di Napoli M, Ageno W, et al. Direct oral anticoagulants for secondary prevention in patients with non valvular atrial fibrillation. Ital J Med 2013;7:8-21.

14. Ntaios G, Papavasileiou V, Diener HC, et al. Nonvitamin-K-antagonist oral anticoagulants versus warfarin in patients with atrial fibrillation and previous stroke or transient ischemic attack: an updated systematic review and meta-analysis of randomized controlled trials. Int J Stroke 2017;12:589-96.

15. Steffel J, Verhamme P, Potpara TS, et al; ESC Scientific Document Group. The 2018 European Heart Rhythm Association Practical Guide on the use of non-vitamin $\mathrm{K}$ antagonist oral anticoagulants in patients with atrial fibrillation. Eur Heart J 2018;39:1330-93.

16. Hong KS, Kwon SU, Lee SH, et al.; Phase 2 Exploratory Clinical Study to Assess the Effects of Xarelto (Rivaroxaban) Versus Warfarin on Ischemia, Bleeding, and Hospital Stay in Acute Cerebral Infarction Patients With Non-valvular Atrial Fibrillation (Triple AXEL) Study Group. Rivaroxaban vs warfarin sodium in the ultra-early period after atrial fibrillation-related mild ischemic stroke: a randomized clinical trial. JAMA Neurol 2017;74:1206-15.

17. Masotti L, Grifoni E, Dei A et al. Ninety-day prognosis of patients receiving direct oral anticoagulants in the early phase of non valvular atrial fibrillation-related acute ischemic stroke: the real life evidence. Thromb Res 2018;172:165-8.

18. Moroni F, Masotti M, Vannucchi V, et al. Confidence in use of direct oral anticoagulants in the acute phase of non valvular atrial fibrillation-related ischemic stroke over the years: a real world single centre study. J Stroke Cerebrovasc Dis 2018;27:76-82.

19. Paciaroni M, Agnelli G, Falocci N, et al. Early recurrence and major bleeding in patients with acute ischemic stroke and atrial fibrillation treated with nonvitamin-k oral anticoagulants (RAF-NOACs) study. J Am Heart Assoc 2017;6.

20. Arihiro S, Todo K, Koga M et al.; SAMURAI Study Investigators. Three-month risk-benefit profile of anticoagulation after stroke with atrial fibrillation: The SAMURAI-Nonvalvular Atrial Fibrillation (NVAF) study. Int J Stroke 2016;11:565-74.

21. Gioia LC, Kate M, Sivakumar L, et al. Early rivaroxaban use after cardioembolic stroke may not result in hemorrhagic transformation: a prospective magnetic resonance imaging study. Stroke 2016;47:1917-9.

22. Seiffge DJ, Traenka C, Polymeris A, et al. Early start of DOAC after ischemic stroke: Risk of intracranial hemorrhage and recurrent events. Neurology 2016;87: 1856-62.

23. Cappellari M, Carletti M, Danese A, Bovi P. Early introduction of direct oral anticoagulants in cardioembolic stroke patients with non-valvular atrial fibrillation. J Thromb Thrombolysis 2016;42:393-8.

24. Monteagudo M, Fernandez-Diaz E, Garcia-Garcia J, et al. Efficacy, safety and tolerability of rivaroxaban for the secondary prevention of stroke in patients with atrial fibrillation in clinical practice. Future Neurol 2015; 10:529-36.

25. Shibazaki K, Kimura K, Aoki J, et al. Early initiation of new oral anticoagulants in acute stroke and TIA patients with nonvalvular atrial fibrillation. J Neurol Sci 2013;331:90-3.

26. Yoshimura S, Koga M, Sato S, et al.; SAMURAI Study Investigators. Two-year outcomes of anticoagulation for acute ischemic stroke with nonvalvular atrial fibrillationSAMURAI-NVAF study. Circ J 2018;82:1935-42.

27. Paciaroni M, Agnelli G, Caso V, et al. Prediction of early recurrent thromboembolic event and major bleeding in patients with acute stroke and atrial fibrillation by a risk stratification schema: the ALESSA score study. Stroke 2017;48:726-32.

28. Deguchi I, Tanahashi N, Takao M. Selection of oral anticoagulants in ischemic stroke patients with nonvalvular atrial fibrillation. J Stroke Cerebrovasc Dis 2018;27:2627-631.

29. Deguchi I, Tanahashi N, Takao M. Timing of treatment initiation with oral anticoagulants for acute ischemic stroke in patients with nonvalvular atrial fibrillation. Circ J 2017;81:180-4.

30. Macha K, Volbers B, Bobinger T et al. Early initiation of anticoagulation with direct oral anticoagulants in patients after transient ischemic attack or ischemic stroke. J Stroke Cerebrovasc Dis 2016;25:2317-21. 